\section{CORONARY ARTERY BYPASS GRAFTING WITH THE INFERIOR EPIGASTRIC ARTERY}

\section{Midterm clinical and angiographic results}

From the Departments of Cardiovascular and Thoracic Surgery a and Cardiology, ${ }^{b}$ Catholic University of Louvain, Cliniques Universitaires UCL de Mont-Godinne, 5530 Yvoir, Belgium.

Read at the Seventy-fourth Annual Meeting of The American Association for Thoracic Surgery, New York, N.Y., April 24-27, 1994.

Address for reprints: M. Buche, MD, Service de Chirurgie Cardiovasculaire et Thoracique, Cliniques Universitaires UCL de MontGodinne, B-5530 Yvoir, Belgium.

Copyright $(1) 1995$ by Mosby-Year Book, Inc. $0022-5223 / 95 \$ 3.00+0 \quad \mathbf{1 2 / 6 / 6 1 4 8 9}$
Between December 1988 and September 1993, 157 patients (141 men, 16 women, average age 60.2 years, range 37 to 78 years) underwent a complete myocardial revascularization with 157 inferior epigastric artery grafts and 285 internal mammary artery grafts (281 in situ, 4 free grafts). A total of 543 distal arterial anastomoses (average 3.4, range two to five per patient) were constructed, 376 with the internal mammary artery and 167 with the inferior epigastric artery. The inferior epigastric artery grafts were anastomosed to two left anterior descending, 5 diagonal, 34 circumflex, and 126 right coronary arteries. The indications for the use of the inferior epigastric artery were the unavailability of conventional conduits in 56 patients and a favorable anatomy or a young age in 101 selected patients. The clinical follow-up averages 31.8 months (range 6 to 62 months). Four patients died early, and there were three perioperative nonfatal myocardial infarctions. Eight patients required early reoperation for thoracic bleeding (2) or drainage of an abdominal parietal collection (6). There were four late deaths ( 2 sudden deaths, 2 noncardiac causes) and one nonfatal myocardial infarction. Angina recurred in nine patients, of whom one required reoperation and three underwent successful percutaneous balloon angioplasty of a native coronary artery (2) or an old saphenous vein graft (1). An early recatheterization was obtained before discharge (average 11 days) in 135 patients: 132 of 135 inferior epigastric artery grafts were patent. Seventy-seven patients underwent a second angiographic restudy 6 to 43 months after the operation. Forty-four of the 48 inferior epigastric artery grafts restudied within the first postoperative year (average 8.5 months) were patent, but eight showed a diffuse narrowing. Twenty-eight of the 29 inferior epigastric artery grafts examined angiographically between 13 and 43 months (average 25 months) were open, and among those 29,25 were widely patent, perfectly matching the receiving coronary artery. Most of the occluded or narrowed inferior epigastric artery grafts were grafted onto coronary arteries with mild stenosis at restudy. Five patients underwent a third angiographic reexamination up to 60 months after the operation (average 39 months). All five inferior epigastric artery grafts were widely patent. The early attrition rate of the inferior epigastric artery, as for any free arterial graft, is probably the result of both the loss of a true pedicle and the need for constructing an additional proximal anastomosis. The fact that the patency rate of the inferior epigastric artery graft seems to remain stable beyond 1 year could suggest a good durability in the future. (J THORAC CARDIOVASC SuRG 1995;109:553-60)

Michel Buche, $\mathrm{MD}^{\mathrm{a}}$ (by invitation), Erwin Schroeder, $\mathrm{MD}^{\mathrm{b}}$ (by invitation), Olivier Gurné, $\mathrm{MD}^{\mathrm{b}}$ (by invitation), Patrick Chenu, $\mathrm{MD}^{\mathrm{b}}$ (by invitation), Jean-Louis Paquay, $\mathbf{M D}^{\mathrm{b}}$ (by invitation), Baudouin Marchandise, $\mathrm{MD}^{\mathrm{b}}$ (by invitation), Philippe Eucher, $\mathrm{MD}^{\mathrm{a}}$ (by invitation), Yves Louagie, $\mathrm{MD}^{\mathrm{a}}$ (by invitation), Robert Dion, $\mathrm{MD}^{\mathrm{a}}$ (by invitation), and Jean-Claude Schoevaerdts, $\mathrm{MD}^{\mathrm{a}}$ (by invitation), Yvoir, Belgium Sponsored by Albert Starr, MD, Portland, Ore.
$T$ he long-term superiority of the internal mammary artery (IMA) over vein grafts for myocardial revascularization has been well established. ${ }^{1,2}$ Consequently, the current trend is to bypass more coronary arteries with arterial conduits by using more extensively both IMAs in combination with other arteries with similar characteristics. The inferior epigastric artery (IEA) is one of those alternative arterial bypass conduits. However, only preliminary results exist for this new graft. ${ }^{3-9}$ In this study, we present our 5-year experience with the use of the IEA for coronary artery bypass grafting (CABG) in 157 patients. 
Table I. Patient characteristics

$\begin{array}{lc}\text { Sex ratio (M/F) } & 141 / 6 \\ \text { Angina CCSC } & \\ \text { CCS class IV } & 74 \\ \text { CCS class III } & 67 \\ \text { CCS class II } & 16 \\ \text { Previous MI } & 86 \\ \text { Previous PTCA } & 17 \\ \text { Reoperation } & 14 \\ \text { Multivascular systemic disease } & 31 \\ \text { Hyperlipidemia } & 84 \\ \text { Hypertension } & 53 \\ \text { Cigarette smoking } & 88 \\ \text { Severe COPD } & 16 \\ \text { Gastrectomy } & 4\end{array}$

CCS, Canadian Cardiovascular Society; $M I$, myocardial infarction; $P T C A$, percutaneous transluminal coronary angioplasty; COPD, chronic obstructive pulmonary disease.

\section{Patients and methods}

Between December 1988 and September 1993, the IEA was used for myocardial revascularization in 157 patients by the same surgeon (M.B.). The patients comprised 141 men and 16 women. The average age was 60 years (range 37 to 78 years). Seventy-four patients were in Canadian Cardiovascular Society class IV, 67 in class III, and 16 in class II. Eighty-six patients had an history of previous myocardial infarction, 17 within the month before the operation. Twelve patients had had one previous CABG operation and two had had two previous CABG operations. One hundred thirty-one patients had three-vessel disease and 26 had two-vessel disease. Twenty-eight had a significant stenosis of the left main coronary artery as well. The average angiographic left ventricular ejection fraction was $60 \%$ (range $29 \%$ to $83 \%$ ). The other characteristics and risk factors for coronary artery disease of the 157 patients are listed in Table I.

Early in our experience, the IEA was used when no or only poor saphenous veins were available because of previous harvesting for arterial bypass procedure, stripping, varicose veins, or severe peripheral arteritis in 56 patients. Three patients undergoing a reoperation had only one IMA available as well.

Subsequently, the IEA graft was used in preference to saphenous vein conduits in 75 young patients ( $\leq 60$ years) with three-vessel disease to achieve a complete arterial myocardial revascularization. It was also used in preference to the right IMA in 26 patients with selected two-vessel disease involving a minor or a distal right coronary artery (RCA) out of reach of the pedicled right IMA. This was a means to preserve the right IMA for the future and to avoid the respiratory and sternal morbidity likely to occur after bilateral IMA harvesting.

We have previously described our operative technique. ${ }^{9,10}$ A selective opacification of one IEA in situ (most of the time the right IEA) is routinely performed before the operation. The IEA is harvested only if its length and size seem adequate to reach and match the target coronary artery. The IEA is taken out through a paramedian infraumbilical incision. The IEA is extensively dissected from its iliac origin to its terminal bifur- cation. The IEA is mobilized with its two satellite veins and the surrounding preperitoneal fat pad. After dissection, the IEA is forcefully sprayed with a solution of papaverine $(40 \mathrm{mg} / 100 \mathrm{ml})$ and wrapped in sponges soaked with the same solution. The IEA is transected only after total body heparinization. After that, the IEA is gently flushed with a mixture of warm heparinized blood of the patient, papaverine $(40 \mathrm{mg} / 100 \mathrm{ml})$, and dipyridamole $(20 \mathrm{mg} / 100 \mathrm{ml})$ and finally is preserved in this medium until it will be grafted. The proximal anastomosis of the IEA graft was constructed onto the ascending aorta in 149 patients. This was done directly in 73 patients and via a short piece of saphenous vein in 76 others when the aortic wall was too thick or the IEA graft was too small (the proximal IEA was anastomosed end to end to an "ultrashort" tube of saphenous vein, which was then grafted to the aorta in 73 patients, or it was anastomosed end to side to the hood or to the proximal part of an old saphenous vein graft in three others undergoing reoperation). Eight IEA grafts that could not reach the diaphragmatic area of the heart from the ascending aorta were anastomosed onto a pedicled IMA (5 right IMA, 3 left IMA, 1 end to side, and 7 end to end).

One hundred twenty-six distal anastomoses of the IEA graft were constructed onto the main RCA (88) or its branches (posterior descending 27; a posterolateral branch 11), 34 onto a marginal branch of the circumflex artery, 2 onto the left anterior descending artery (LAD), and 5 onto its diagonal branches. Two hundred eighty-five IMAs were used as well (154 left IMA, 131 right IMA, 281 pedicled, 4 free). The left IMA, when available, was directed to the LAD and its diagonal branches and the right IMA was most of the time passed through the transverse sinus for grafting the marginal branches of the circumflex artery. A total of 543 arterial distal anastomoses were constructed (3.4 per patient; maximum 5); 167 were constructed with IEA grafts. Twenty-nine patients received one IMA and one IEA graft, and 128 patients received two IMA grafts and one IEA graft. Five patients underwent a concomittant carotid endarterectomy (Table II).

\section{Results}

Perioperative results. Four patients died in the intensive care unit within the first postoperative day: two patients of intractable left ventricular failure, one of sudden ventricular fibrillation, and one of acute tamponade resulting from a subtotal disruption of a direct aortoepigastric anastomosis. The IEA in all four patients was used to bypass the main RCA. Three patients had a perioperative nonfatal myocardial infarction (1 Q-wave infarction; 2 new left bundle branch block). The early postoperative angiograms obtained before discharge in these three patients showed that all the IEA and IMA grafts and anastomoses were well patent. Two patients underwent a thoracic reexploration for bleeding and six required drainage of an abdominal wall collection. 
Two of them had an incisional hernia later. No sternal complications occurred.

Late results. The clinical follow-up is complete and averages 32 months ( 6 to 62 months). Two patients died suddenly, the first 1 month after the operation and the second 2 years later. The IEA anastomosed to one marginal branch of the circumflex artery and both pedicled IMAs grafted onto the LAD and the main RCA were widely patent at day 10 in the first patient. A recatheterization obtained in the second patient a few weeks before she died had shown that the IEA graft anastomosed to the main RCA was widely patent. However, a free IMA grafted onto the LAD was occluded and in addition an aortic stenosis that was not significant at the time of the CABG operation had seriously worsened. A reoperation was advised but the patient refused. Two other patients died of noncardiac causes (1 cancer and 1 lower limb gangrene) within the first year after the operation.

One patient had a nonfatal myocardial infarction in a myocardial area not bypassed with the IEA 2 years after the operation. The IEA and both IMA grafts restudied at this time were widely patent. Nine patients had recurrence of exertional angina ( 8 of them within the first postoperative year). Angiograms obtained for this reason in all of them correlated the recurrence of symptoms with occlusion of the IEA graft in four patients, occlusion of IMA graft or IMA anastomosis in two, appearance of a new stenosis in two old saphenous vein grafts, and progression of the coronary artery disease distally to well patent IMA grafts in two patients. Among these nine patients, three underwent a successful percutaneous balloon angioplasty of a native coronary artery (2) or an old saphenous vein graft (1). One patient required regrafting of a posterior descending coronary artery with a pedicled right IMA.

Early angiograms. Postoperative angiograms were obtained in 135 patients (88\%) within 2 weeks after the operation. Despite preoperative informed consent, 15 patients refused any postoperative angiographic reexamination and three had obvious contraindications for further recatheterization because of a precarious vascular access or severe calcifications of the ascending aorta. Three IEA grafts were occluded and 132 ( $97 \%$ ) were patent; of these 132 patent IEA grafts, 120 had a perfect angiographic appearance and 12 showed either significant anastomotic stenoses (3 proximal, 2 distal) or focal wall irregularities. Direct injection of nitrates into the IEA grafts had no influence on these irregularities. Two of the three IEA
Table II. Sites of IEA and IMA anastomoses

\begin{tabular}{|c|c|c|}
\hline & $\begin{array}{c}\text { IEA } \\
\text { (157 grafts) }\end{array}$ & $\begin{array}{c}I M A \\
\left(285 \text { grafts }^{*}\right)\end{array}$ \\
\hline RCA/PD/PLB & 126 & 20 \\
\hline Circumflex & 34 & 114 \\
\hline LAD/diagonal & 7 & 242 \\
\hline
\end{tabular}

$P D$, Posterior descending; $P L B$, posterolateral branch.

${ }^{*}$ Of the 285 grafts, 281 were pedicled and 4 were free.

grafts that were occluded were directly anastomosed onto the aorta and one was proximally sutured onto the hood of an old saphenous vein graft.

Comparatively, all 249 IMA grafts (and 318/319 IMA anastomoses) were patent.

Late angiograms. Forty-eight patients (including 8 symptomatic patients) underwent a subsequent angiographic restudy between 6 and 12 months after the operation (average 8.5 months). Four IEA grafts were occluded and 44 were patent. Of these 44 patent IEA grafts, eight had a diffused narrowing that could not be reversed by direct injection of vasodilators into the IEA grafts and $36(75 \%)$ were widely patent and free of any angiographic abnormality. Surprisingly, one of these 36 widely patent grafts was occluded at day 10 (Fig. 1).

Twenty-nine other patients were recatheterized from 13 to 43 months after the operation (average 25 months). One IEA graft was occluded and 28 were patent. Of these 28 patent IEA grafts, three were diffusely narrowed and $25(86 \%)$ were widely patent and perfectly matched the bypassed coronary artery.

In total, five of the 77 IEA grafts restudied between 6 and 43 months after the operation (average 14.8 months) were occluded; 11 were diffusely narrowed, and 66 remained widely patent $(79 \%)$.

Of the five IEA grafts that became occluded, four were anastomosed onto the aorta ( 2 directly and 2 via a short tube of saphenous vein) and one was anastomosed proximally end to end onto a pedicled right IMA (Tables III and IV).

It must be pointed out that eight of the 11 IEA grafts that became narrowed were used to bypass RCAs showing mild stenosis at the time of the restudy. On the contrary, 37 of 40 IEAs grafted onto coronary arteries that were occluded at the time of the operation were widely patent at time of the second restudy.

In comparison, 132 of 135 IMA grafts (97\%) and 167 of 171 IMA anastomoses were patent and intact. 

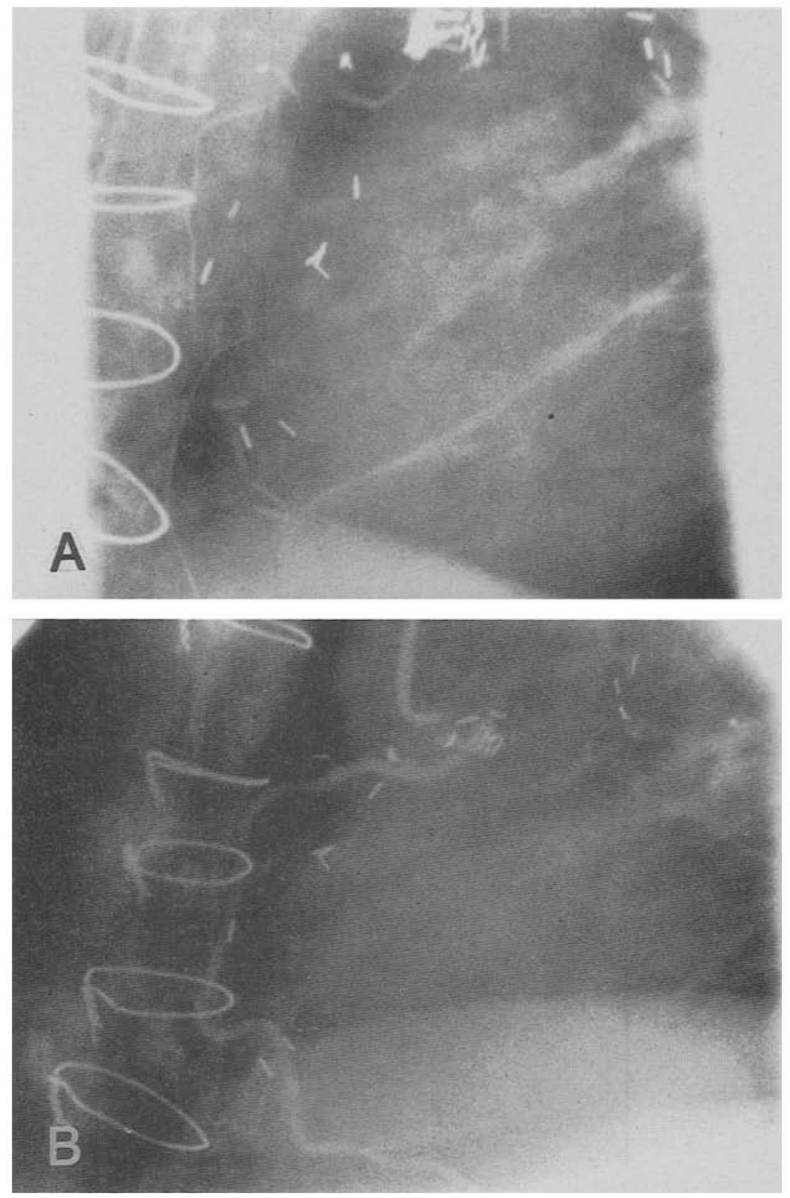

Fig. 1. A, Ten-day postoperative angiogram of a free IEA anastomosed to the RCA: the distal portion of the graft and the receiving $\mathrm{RCA}$ are not filled by the contrast medium. B, Six months later the IEA is widely patent and fills the RCA.

Five patients underwent a third angiographic follow-up study up to 5 years after the operation (average 39 months). All five IEA grafts and 10 IMA grafts placed in these patients were patent and intact.

\section{Discussion}

The IEA has recently been used for myocardial revascularization. Histologic similarities ${ }^{6,9,11}$ with the IMA suggest that its patency rate will be comparable with that of free IMA grafts, but no study has yet validated this assumption. In March 1990, Puig and associates ${ }^{3}$ reported on 22 patients who received 24 IEAs as CABGs. Seventeen of them underwent postoperative coronary arteriography within 10 days after the operation. Sixteen of 18
Table III. IEA graft patency

\begin{tabular}{lcccc}
\hline \multicolumn{4}{c}{ Postop. angiogram } \\
\hline & First & \multicolumn{2}{c}{ Second } & Third \\
\cline { 3 - 5 } \cline { 3 - 5 } & & $8.5 \mathrm{mo}$ & $25 \mathrm{mo}$ & $39 \mathrm{mo}$ \\
& Day 11 & $(6-12 \mathrm{mo})$ & $(13-43 \mathrm{mo})$ & $(16-60 \mathrm{mo})$ \\
\hline Patent & $132 / 135$ & $44 / 48$ & $28 / 29$ & $5 / 5$ \\
Intact & $120 / 135$ & $36 / 48$ & $25 / 29$ & $5 / 5$ \\
\hline
\end{tabular}

Table IV. IEA graft occlusion/technique used for proximal anastomosis

\begin{tabular}{lcc}
\hline & $\begin{array}{c}\text { Early occlusion } \\
\text { (135 IEA grafts) }\end{array}$ & $\begin{array}{c}\text { Late occlusion } \\
\text { (77 IEA grafts) }\end{array}$ \\
\hline On aorta via saphenous vein & $1 / 60$ & $2 / 30$ \\
On aorta directly & $2 / 67$ & $2 / 42$ \\
On IMA & $0 / 8$ & $1 / 5$ \\
\hline
\end{tabular}

IEAs were patent. Shortly after, Mills and Everson ${ }^{4}$ and Mills, Everson, and Hockmuth ${ }^{5}$ reported on their experience with the IEA graft in 18 patients. The preliminary results were excellent: three IEA grafts restudied within 10 days after the operation were all widely patent. The subsequent results were more disappointing: five IEA grafts restudied up to 20 months were either occluded or narrowed. Barner, ${ }^{6}$ Milgalter, ${ }^{7}$ and their associates also reported on their use of the IEA for CABG. Their results regarding the relief of pain were excellent. However, no angiographic results in their studies could prove the patency of the IEA graft. More recently, Perrault and coworkers ${ }^{8}$ placed the IEA graft in 18 patients. A postoperative angiogram was obtained in 14 of them before they were discharged from the hospital. Six IEAs were occluded and only eight were patent. In addition, one patent IEA showed diffused irregularities. To our knowledge, no other postoperative angiographic results concerning the IEA grafts have been published by these authors.

In our study, the early patency rate of the IEA grafts established on the sound basis of 135 recatheterizations done within 2 weeks after the operation is high (97\%) and does not differ from the patency rate of the IMA grafts (99\%).

Puig and associates ${ }^{3}$ suggested that the patency rate of IEA grafts was dependent on the technique used for the aortoepigastric anastomosis. In their study, $25 \%(2 / 8)$ of IEA grafts directly sutured onto the aorta were occluded, whereas $100 \%(10 / 10)$ of 
IEA grafts proximally anastomosed to the aorta by means of a small piece of saphenous vein or bovine pericardial patch were patent. We are also convinced that the early patency of the IEA graft depends mainly on the operative technique and that grafting the IEA onto the aorta is probably one of the most demanding parts of the procedure likely to affect the early patency rate of the graft. However, in our study, there seems to be no difference in patency whether the IEA grafts were directly sutured onto the aorta or not. We must admit that direct aortoepigastric anastomoses were performed only when favorable conditions were present, including a smooth aortic wall and a large IEA.

Segmental irregularities that could not be released by direct injection of nitrates into the graft were found on seven IEA grafts at the time of the early recatheterization. Perrault and coworkers, ${ }^{8}$ in their study, noted similar findings and suggested early atherosclerotic changes of the graft. However, it is probable that those irregularities, if not present when the IEA was harvested, could have been caused by perioperative damage to the graft. In our study, two of the IEA grafts that showed irregularities on the early postoperative angiogram were restudied 6 months later and had regained a smooth appearance. Therefore, those irregularities when observed in the early postoperative period do not seem to be pejorative signs for the subsequent evolution of the graft.

We are obviously more concerned about the late diffused narrowing of IEA grafts that were angiographically faultless at time of the early recatheterization. Similar postoperative diffused narrowing has been observed after the use of IMA or gastroepiploic artery grafts. Two recent quantitative angiographic studies have shown that postoperative narrowing of IMA or gastroepiploic artery grafts occurs when native blood flow is well maintained in the bypassed coronary artery, which makes the competitive flow through the graft unnecessary. ${ }^{12,13}$ In our study, most of the IEA grafts that became diffusely narrowed were also anastomosed onto coronary arteries with only mild stenosis and good native blood flow on the late postoperative angiogram. A similar adverse competition of flow between the IEA graft and the bypassed coronary artery could therefore be one of the causes of the postoperative narrowing of the IEA grafts. Dincer, ${ }^{14}$ Aris, ${ }^{15}$ Toyama, ${ }^{16}$ Mills, ${ }^{5}$ and their associates have reported a few cases of postoperative narrowing or even occlusion of pedicled or free IMA grafts that

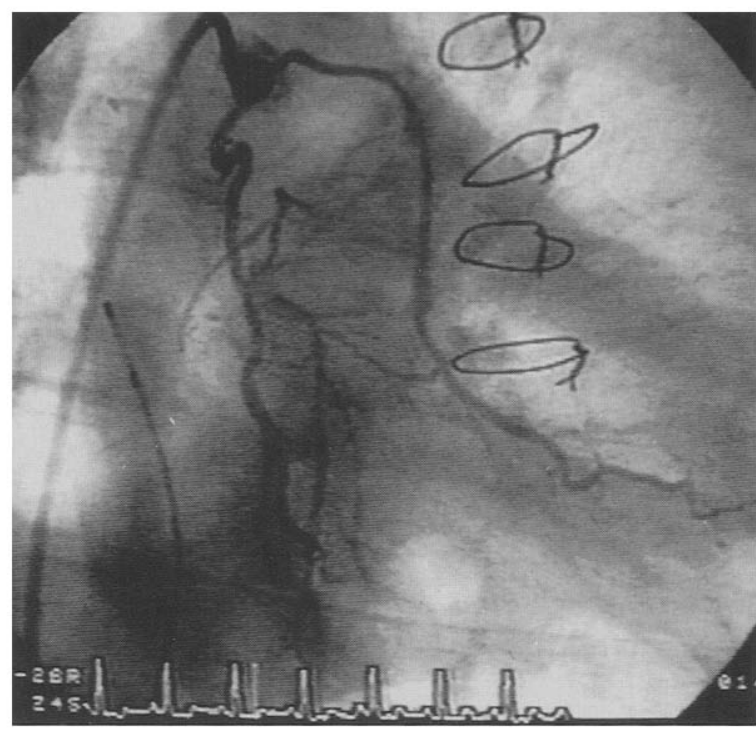

Fig. 2. Sixteen-month postoperative angiogram of a free IEA anastomosed to an obtuse marginal artery and a free IMA anastomosed to the mean RCA.

completely resolved when the stenosis of the bypassed coronary artery increased. Similarly, one of the IEA grafts of our study, which was virtually occluded on the early postoperative angiogram, was shown to be widely patent 6 months later (see Fig. 1 ). On the basis of this observation, we could suggest, as it was done for IMA grafts, that postoperative narrowing of IEA grafts is reversible so long as the graft has not been irreversibly damaged during the operation. However, the real prognosis of postoperative diffuse narrowing of the IEA grafts remains uncertain.

Of the IEA grafts restudied in this study after an average follow-up of 15 months, $79 \%$ are widely patent, have a good smooth appearance, and perfectly match the bypassed coronary artery (Figs. 2 and 3). A few years ago, Loop and coworkers ${ }^{17}$ showed that $77 \%$ of free IMA grafts restudied within 18 months of operation were patent. More recently, Dion, ${ }^{18}$ Acar, ${ }^{19}$ and their colleagues reported similar patency rates of free IMA grafts 13 and 9 months after the operation. On this basis, the midterm patency rate of free IMA and free IEA grafts used for CABG are similar, and the fact that the patency rate of IEA grafts remains stable after the first postoperative year probably indicates comparable long-term durability.

As expected, the midterm patency rate of pedi- 

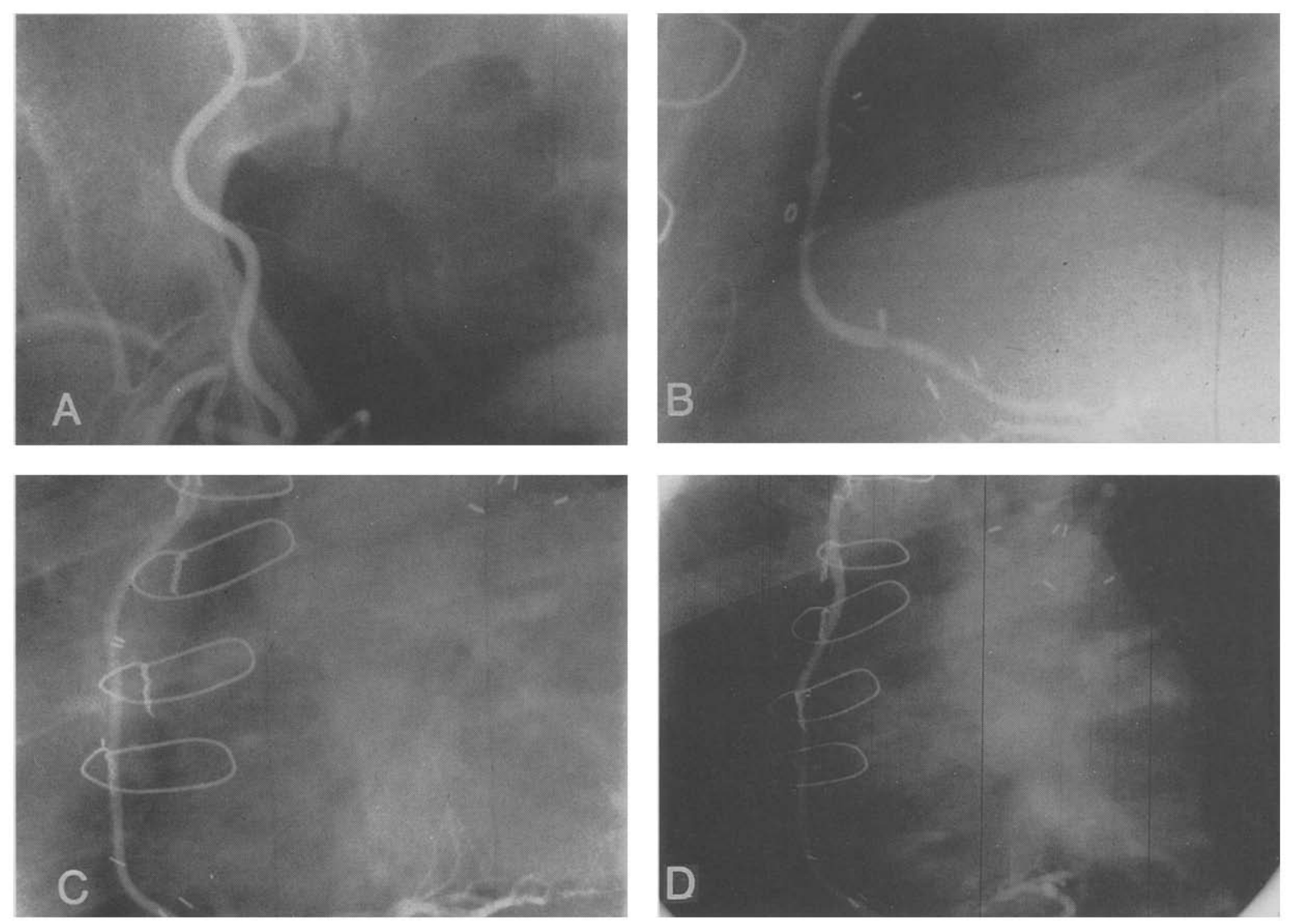

Fig. 3. Sequential angiograms of an IEA graft. A, In situ. B, Grafted on the posterior descending branch artery at day $10 . \mathbf{C}$, Six months later. D, Five years later. Note the resolution of the irregularities observed at day 10 on the subsequent angiograms. (C is reprinted with permission from Buche M, Schoevaerdts J-C, Louagie Y, et al. Use of the Inferior Epigastric Artery for Coronary Bypass. J Thorac Cardiovasc SuRG 1992;103:665-70.)

cled IMA grafts remains excellent and is identical to that observed on postoperative day 11.

The early attrition rate of both free IEA and free IMA grafts is caused by the loss of their pedicle, and the implications of pedicle loss involve more than the need to reconstruct a proximal anastomosis to restore arterial inflow. Mills, Everson, and Hockmuth $^{5}$ have recently suggested that both arterial and venous blood supplies of the free IEA and the pedicled IMA grafts should be reconnected in a $Y$ fashion as a means for the IEA graft to function as a true pedicle. However, despite the merits of this suggestion, we remain reluctant to routinely apply this technique because of the potential risk to compromise the patency of the donor IMA.

Acar and associates, ${ }^{19}$ in a recent study, have shown that the use of calcium channel blockers improved the midterm patency rate of the radial artery grafts used for CABG by counteracting the tendency of the radial artery to spasm. It is likely that these drugs could improve the patency rate of the IEA graft (which is also to a lower degree a muscular artery) in a similar way. Therefore, we are now using calcium channel blocker in the early postoperative period. However, long-term studies of the patients having received this adjuvant therapy have not yet been conducted.

\section{Conclusion}

The midterm patency rate of free IEA grafts is inferior to that of pedicled IMA grafts, probably because of the loss of a true pedicle. After an initial period of attrition during the first postoperative year, the later patency rate of the IEA graft seems to become stable. Therefore, the IEA seems to be a valuable alternative arterial conduit, especially in 
patients with no conventional conduit available or to bypass coronary arteries that could not be grafted with a pedicled IMA.

\section{REFERENCES}

1. Grondin CM, Campeau L, Lesperance J, Enjalbert M, Bourassa MG. Comparison of late changes in internal mammary artery and saphenous vein grafts in two consecutive series of patients 10 years after operation. Circulation 1984;70(Suppl):I208-12.

2. Loop FD, Lytle BW, Cosgrove DM, et al. Influence of the internal mammary artery graft on 10-year survival and other cardiac events. N Engl J Med 1986;314:1-6.

3. Puig LB, Ciongolli W, Cividanes GVL, et al. Inferior epigastric artery as a free graft for myocardial revascularization. J THORAC CARdiovasc Surg 1990:99: 251-5.

4. Mills NL, Everson CT. Technique for use of the inferior epigastric artery as a coronary bypass graft. Ann Thorac Surg 1991;51:208-14.

5. Mills NL, Everson CT, Hockmuth DR. Free arterial grafts. Curr Opin Cardiol 1991;6:898-903.

6. Barner HB; Naunheim KS, Fiore AC, Fischer VW, Harris $\mathrm{HH}$. Use of the inferior epigastric artery as a free graft for myocardial revascularization. Ann Thorac Surg 1991;52:429-37.

7. Milgalter E, Pearl JM, Laks H, et al. The inferior epigastric arteries as coronary bypass conduits. J ThORAC Cardiovasc Surg 1992;103:463-5.

8. Perrault LP, Carrier M, Hebert Y, Cartier R, Lecler $\mathrm{Y}$, Pelletier LC. Early experience with the inferior epigastric artery in coronary artery bypass grafting. J Thorac Cardiovasc Surg 1993;106:928-30.

9. Buche M, Schoevaerdts JC, Louagie Y, et al. Use of the inferior epigastric artery for coronary bypass. J Thorac Cardiovasc SuRg 1992;103:665-70.

10. Buche M, Schroeder E, Devaux P, Louagie Y, Schoevaerdts JC. Right internal mammary artery extended with an inferior epigastric artery for circumflex and right coronary bypass. Ann Thorac Surg 1992;54: 381-3.

11. Van Son JAM, Smedts F, Vincent JG, Van Lier HJJ, Kubat K. Comparative anatomic studies of various arterial conduits for myocardial revascularization. $\mathbf{J}$ Thorac Cardiovasc Surg 1990;99:703-7.

12. Seki $\mathrm{T}$, Kitamura S, Kawachi K, et al. A quantitative study of postoperative luminal narrowing of the internal thoracic artery graft in coronary artery bypass surgery. J Thorac Cardiovasc Surg 1992;104: 1532-8.

13. Nakao T, Kawaue Y. Effect of coronary revascularization with the right gastroepiploic artery. J THORAC Cardiovasc Surg 1993;106:149-53.

14. Dincer B, Barner HB. The "occluded" internal mammary artery graft: restoration of patency after appar- ent occlusion associated with progression of coronary disease. J Thorac Cardiovasc Surg 1983;5:318-22.

15. Aris A, Borras X, Ramio J. Patency of internal mammary artery grafts in no-flow situations. J THORAC CardiovasC Surg 1987;93:62-4.

16. Toyama AA, Sato M. A case report of bilateral free internal mammary artery bypass grafting reoperation: spontaneous resolution of stenotic left anterior descending artery graft one year after revascularization. Nippon Kyobu Geka Gakkai Zasshi 1990;38:341-5.

17. Loop FD, Lytle BW, Cosgrove DM, Golding LAR, Taylor PC, Stewart RW. Free (aorta-coronary) internal mammary artery graft. J THORAC CARDIOvasC SURG 1986;92:827-31.

18. Dion R, Etienne PY, Verhelst R, et al. Bilateral mammary grafting: clinical, functional and angiographic assessment in 400 consecutive patients. Eur J Cardiothorac Surg 1993;7:287-94.

19. Acar C, Jebara VA, Portoghese M, et al. Revival of the radial artery for coronary artery bypass grafting. Ann Thorac Surg 1992;54:652-60.

\section{Discussion}

Dr. Bruce W. Lytle (Cleveland, Ohio). This is important information. Despite the fact that long-term patency was not perfect, about $80 \%$, in these days with patients undergoing multiple reoperations and lacking conduits for bypass grafting, a strategy that results in an $80 \%$ long-term patency rate is not to be discarded.

You point out that a number of grafts had a "string sign," an abnormal but not totally occluded graft. First, do you think that was caused by competitive flow? Were the lesions in the native coronary vessels not severe? Second, was the appearance of the string sign absolutely predictive of graft occlusion? Did you study any grafts that had a string sign at the initial study but looked better on a subsequent angiogram?

Dr. Buche. Dr. Lytle, we have indeed observed in our study some cases of early postoperative narrowing or even occlusion of IEA grafts that had completely resolved at the time of a second angiographic study (see Fig. 1 of the manuscript).

Dr. Hisayoshi Suma (Tokyo, Japan). I congratulate Dr. Buche for presenting very important information about the IEA that validates the midterm angiographic result of its patency.

Although your result is very good, I think the use of this free arterial graft poses two potential risks. One risk is the difficulty of the proximal anastomosis when the ascending aorta was thickened or diseased with atherosclerosis. The other risk is spasm of the graft.

What is the next best choice for the inflow site when you find that the ascending aorta is not suitable for the proximal anastomosis? Did you give any special pharmacologic treatment to avoid spasm during and after the operation, including intraoperative preservation of the graft and postoperative drug administration?

Dr. Buche. It is likely that the patency rate of the IEA graft will be best when grafting the LAD, but the left IMA 
is the graft of choice to bypass the LAD. Moreover, in our study, the pedicled right IMA anastomosed to the circumflex artery also provides excellent results. Therefore, we believe that the free IEA graft should be used only for the $\mathrm{RCA}$ or the distal branches of the circumflex not in reach of pedicled IMA grafts.

In answer to your second question, we simply flush the IEA during the operation with a solution of blood, heparin, papaverine, and dipyridamole. Recently, we have introduced the use of calcium channel blocker during the postoperative period, but we have not yet obtained follow-up angiograms in those patients.

Dr. Charles A. Dietl (Danville, Pa.). The current trend for using more arterial conduits resulted from the demonstrated poor long-term patency rate of vein grafts. Thus the rationale for total arterial revascularization is to minimize the prevalence of recurrent symptoms and to minimize the risk of late events, such as myocardial infarction, reoperations, and death. However, several studies suggest that the anatomic patency of a graft is not always equivalent to physiologic adequacy.

In our experience with 210 patients with multiple arterial grafts, we have used 244 IMAs, 108 pedicled right gastroepiploic arteries, 155 radial arteries, and 89 IEAs.

We used the IEA with great enthusiasm in 1991 and 1992. Since November of 1992, we have almost abandoned its use, because we compared several characteristics of all four types of arterial conduits, and we obtained the following findings:

The mean length of the IEA was $10.7 \mathrm{~cm}$, compared with $21.5 \mathrm{~cm}$ for the radial artery and $17 \mathrm{~cm}$ for the IMA and the right gastroepiploic artery in situ. The mean diameter at the anastomotic site was $1.25 \mathrm{~mm}$ for the IEA compared with $2.35 \mathrm{~mm}$ for the radial artery, $1.72 \mathrm{~mm}$ for the gastroepiploic artery, and $1.75 \mathrm{~mm}$ for the IMA $(p<0.05)$.

An even more important predictor of the physiologic adequacy and reliability of a graft is the flow rate. The mean flow rate of the IEA was only $36 \mathrm{ml} / \mathrm{min}$, which is inadequate when compared with $140 \mathrm{ml} / \mathrm{min}$ for the radial artery in situ before it was removed, $124 \mathrm{ml} / \mathrm{min}$ for the pedicled right gastroepiploic artery, and $128 \mathrm{ml} / \mathrm{min}$ for the IMA. There was a significant difference $(p<0.01)$ in all cases, compared with the IEA.

The prevalence of intraoperative spasm was $3.4 \%$ for the IEA compared with $3.7 \%$ for the gastroepiploic artery (when the antegastric route was used) and only $1 \%$ when the retrogastric route was used, which requires a shorter segment of gastroepiploic artery. The prevalence of spasm was $2.6 \%$ for the radial artery and $1.6 \%$ for the IMA.

These are significant observations, and for this reason we seldom use the IEA (occasionally, we use it to bypass the diagonal artery).

In summary, the functional status of a graft is more important than its mere patency.

I have two questions for Dr. Buche: Why use the IEA, particularly for the RCA or the posterior descending branch, when there are other, more suitable, and more dependable grafts, such as the pedicled right gastroepiploic artery?

Second, have you been using routinely intraoperative and postoperative diltiazem?

Dr. Buche. We try to use the IEA only when the conditions are ideal. We usually bypass the most important coronary arteries (the $\mathrm{LAD}$ and most often the circumflex artery) with the pedicled IMA, and the IEA is usually directed to minor or distal RCA.

There is no doubt that a preoperative evaluation of the IEA in situ is the most important part of the operation to select the patients having an adequate IEA that can reach and match the target coronary artery.

Dr. Antonio Calafiore (Chieti, Italy). In Chieti, we implanted 115 IEAs in 108 patients. Our technique is slightly different from yours. We do not anastomose the IEA directly to the aorta, for many reasons. The first one is that there is often a mismatch between the aortic wall and the wall of the graft. Furthermore, the aortic wall is often diseased.

The second reason is that the $\mathrm{dP} / \mathrm{dt}$ in the ascending aorta is higher than in the native position of the graft. The higher wall stress can be at the basis of intimal hyperplasia and can cause early graft failure.

Another reason is that the internal diameter of the graft is often smaller after the first muscular branch, so we use the first centimeters of this artery up to this point.

For all these reasons, all IEAs are anastomosed directly to the IMA or to another arterial conduit connected to the IMA before cardiopulmonary bypass.

Using this technique of performing all of our proximal anastomoses before cardiopulmonary bypass, we had a patency rate of our IEAs of more than $95 \%$ after 1 year. We think that this technique can limit the problem that you can have with aortic anastomosis. Moreover, the early attrition rate owing to technical problems and to the physiologic adaptability of the graft can be lowered. 